\title{
Insufficient efforts to boost maternal health
}

A summit of global health leaders focused on infant child and maternal health in Toronto May 27-29, revealed a growing consensus that a handful of simple lowcost interventions are reducing high mortality levels that long seemed intractable in scores of underdeveloped countries.

But many at the three-day Saving Every Woman, Every Child: Within Arm's Reach Summit also expressed the conviction that the targets set in the Millennium Development Goals (MDGs) in 2000 will not be met by the 2015 deadline. The MDGs are a set of promises that included reducing 1990 levels of under-five child mortality by two-thirds and maternal mortality by three-quarters.

"Our efforts have been insufficient," said the Aga Khan, head of a foundation that has received $\$ 240$ million in grants from the Canadian government's \$2.85-billion Muskoka Initiative for child and maternal health. "We have not met the MDGs."

In a detailed explanation of which interventions work best, Jakaya Kikwete, president of the United Republic of Tanzania, noted that his country has increased health expenditures five-fold since 2005 and used the money to combat child and maternal mortality through expanded vaccination programs, family planning services and access to public health facilities.

That simple formula, Kikwete explained, has allowed Tanzania to meet its MDG target for under-five child mortality. But in the case of maternal mortality, "we are far from the target."

A key problem, he explained, is that only $51 \%$ of children are born in health facilities. "So many births still happen at home under care of traditional birth attendants who don't have the right skills."

The focus on the role of skilled birth attendants in reducing child and maternal mortality was echoed by several other influential speakers at the sum-

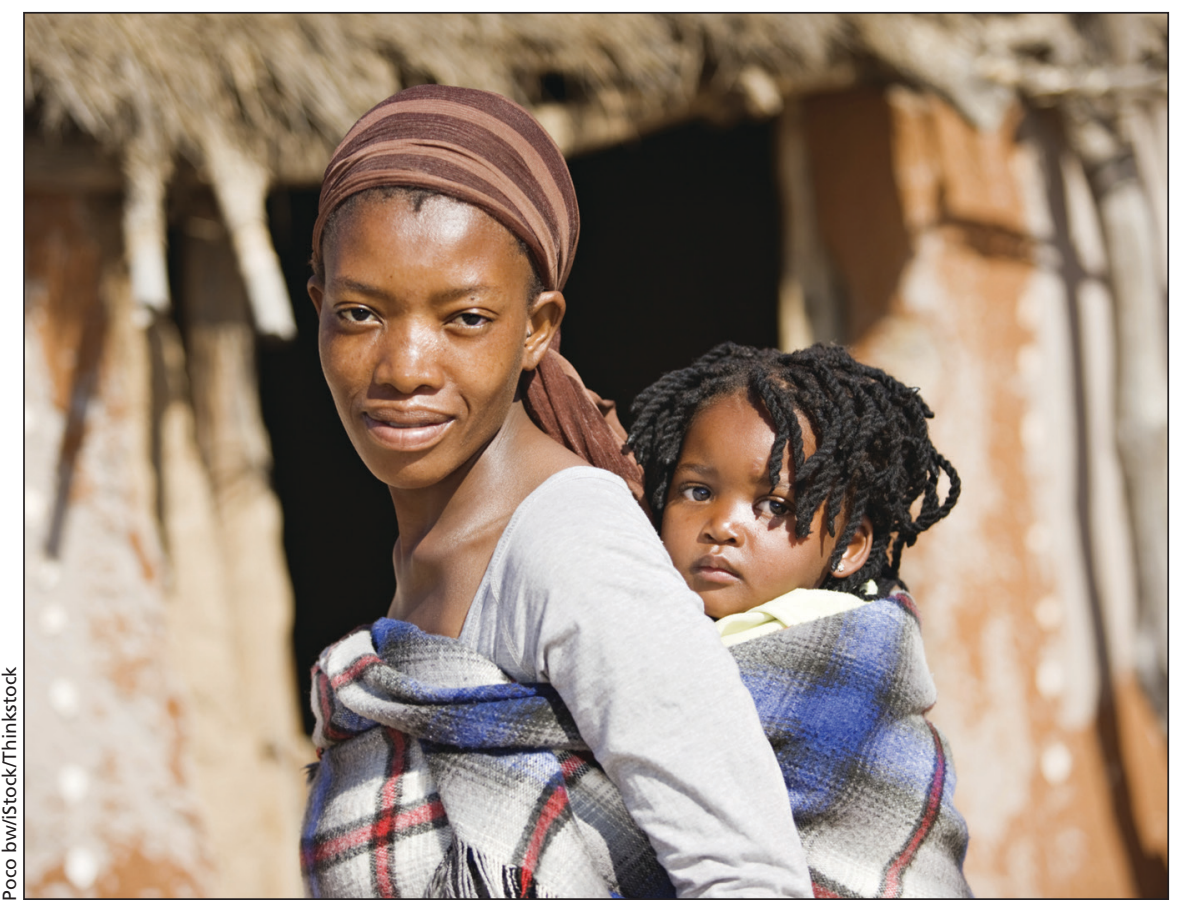

Improvements in immunization, nutrition, family planning and the number of skilled birth attendants could greatly improve maternal health.

mit, including Anthony Lake, executive director of UNICEF, Queen Rania Al Abdullah of Jordan, and Melinda Gates, co-chair of the Bill and Melinda Gates Foundation.

The need for family planning, contraception and maternal, newborn and child health, was emphasized by both Kikwete and Gates. "If women can plan their families, they are more likely to space their pregnancies," said Gates. "If women can space their pregnancies, they are more likely to be healthy and so are their babies."

But in an open letter released during the summit, 10 groups from six African countries, including Tanzania, noted that of the $\$ 2.28$ billion spent from the Muskoka Initiative funding only $0.55 \%$ has been spent on family planning. This amounts to $\$ 12.8$ million since 2010 . Worldwide, 222 million women lack access to a range of modern methods of contraception.

The letter stated that "[r]esearch shows that serving all women in developing countries who currently have an unmet need for modern methods of contraception would prevent an additional 54 million unintended pregnancies, 16 million unsafe abortions and seven million miscarriages; this would also prevent 79000 maternal deaths and 1.1 million infant deaths." The 10 groups called on the summit "to recognise the vital role that access to lifesaving family planning plays in maternal, newborn and child health."

Other groups monitoring Canada's efforts to promote maternal and child health have complained that the federal government will not use the Muskoka Initiative to fund programs that support abortion.

Alongside the calls for a focus on family planning, skilled birth attendants and immunization, numerous speakers at the summit, which was convened by Prime Minister Stephen Harper, strongly endorsed the need for improved nutrition as a crucial life-saving step.

Noting that two-billion people are affected by "hidden hunger," Joel Spicer, president of the Ottawa-based 
Micronutrient Initiative, which has received $\$ 230$ million in federal funding for its vitamin $\mathrm{A}$ and nutrition programs, argued that half of the 6.3 million children who currently die before reaching the age of five could be saved with low-cost nutrition interventions.
Dr. Mickey Chopra, chief of health for UNICEF, said that the summit's focus on this "relatively narrow package of interventions that can be universally achieved" is rooted in a strong evidencebase-base. "Gender empowerment" measures for girls and women including investments in education have also yielded important health dividends. "I think family planning is another investment area that clearly delivers important results," Chopra stressed. "It's time to prioritize these things." - Paul Christopher Webster, Toronto, Ont.

CMAJ 2014. DOI:10.1503/cmaj.109-4821 